\title{
Printed Sleeve Monopole Antenna
}

\author{
Salman Naeem Khan and Muhammad Ashfaq Ahmed \\ Department of Physics \\ COMSATS Institute of Information Technology \\ Pakistan
}

\section{Introduction}

Sleeve antenna dates back to 1947 with its applications in high frequencies by [Bock 1947]. A series of consequent designs and rigorous analysis for such kind of antennas was extensively carried in the preceding years [Norgorden, 1950, King 1965, Poggio, 1966]. Furthermore, [Rispin, 1988] discussed thin-wire analysis for sleeve antennas by studying the standing wave current on the antenna surface. The impedance and pattern of the sleeve monopole antenna was studied in detail by [Wunsch 1998] with the help of Fourier series representation of its surface current. Since then, sleeves have widely been used in multiband communication systems to achieve multi-resonances, miniaturization and wide impedance bandwidth. The sleeve, when applied as extension of ground plane behaves like an additional parasitic element that generates extra resonant mode. The additional resonant mode offered by the sleeve can either be used for dualband/multiband operation or if the extra mode is in close proximity then it combines with the fundamental mode to improve overall bandwidth. On the other hand, ground shorted inset sleeve leads to formation of a virtual feed to excite low resonant mode and is simple tool for antenna miniaturization.

Although UWB antennas have been the interest of engineers over the decade but the recent attraction in the design of such antennas was initiated after the official bandwidth allocation by (FCC, 2002). In addition, after the growth of telecom industry, more and more high speed devices are emerging in the competitive telecom markets with many different built in communication systems working at different frequencies requiring more and more bandwidth to perform those operations. This requires antennas with ultra-wide impedance bandwidth. On the technical side, UWB systems provide high data rates along with large channel capacity, immunity to multipath interference, low complexity, low power consumption and coexistence with other wireless systems [Zhong, 2010]. The real efforts toward UWB antenna design started when [Honda et. al., 1992] proposed a circular disk monopole antenna for the first time to be used for indoor TV systems in Japan. After that, several novel techniques have been introduced by many researchers to achieve ultra widebandwidth requirement. The traditional method is to use a thicker substrate with small relative permittivity substrate. The thickness and permittivity of the substrate is comparison among its availability, usage and price. Therefore, it is not an open choice for the antenna designer. Although, the thicker substrate can improve the impedance bandwidth up to $10 \%$. However, the surface waves are generated for thicker substrate and degrades antenna performance. The other methods include use of different shapes of radiator, optimization of 
device dimensions (e.g. ground and substrate size, substrate types etc.) and modified shape of radiator or ground. Therefore, if the ground is to be modified to achieve UWB operation, sleeves are one of the suitable alternatives. The length and distance of sleeves with respect to ground can easily be optimized to achieve ultra wide-bandwidth. However, most of the literature with reference to sleeve antenna is either focused on multiband/wide-band operation or for size miniaturization.

The use of sleeves for obtaining impedance matching up to UWB is the main focus of this chapter. The chapter is organized by studying the in-depth details how different types of parasitic element as extension of ground (ground shorted sleeve, gap sleeve and inset sleeve) can be used to tailor the impedance bandwidth with optimal performance of the radiator in the first section. Different types of sleeve UWB antenna previously found in literature will be presented in second section with quantitatively analysis in terms of impedance bandwidth and compactness. In the last section, rectangular and diamond shaped sleeve UWB antennas are proposed for UWB performance. The analysis of sleeve UWB antenna will also be explained on the basis of transmission line model of antenna and characteristics modes to get insight details of the sleeves behavior and their effect on the impedance bandwidth.

\section{Sleeve antenna}

Monopole antennas have widely been used in communication and are well known for their simplicity and ease of use. A simple monopole antenna with ground plane modification (ground shorted cylinder around monopole) is the simplest form of sleeve antenna (Fig. 1). Generally, a monopole of half wavelength long, the upper half (quarter wavelength) is open while the lower half is covered with ground is the fundamental known sleeve design. The sleeve basically moves the feed location up the monopole (i.e. virtual feed point) that depends on the length of sleeve. This sleeve monopole has better impedance match to transmission line as compared to the traditional monopole. Decades earlier it was mentioned in [Kraus 1988], that the ground plane degenerates into sleeve with maximum radiation perpendicular to the axis of antenna. The sleeve increases the bandwidth of the monopole due to same current at feed point over the wider range of frequencies [Milligan, T. A., 2005]. This provides an affordable control on the impedance matching over wider bandwidth range.

In order to maintain a certain level of comparison and simplicity, Fire-Resistant (FR-4) substrate $\left(\varepsilon_{r}=4.5 @ 2.5 \mathrm{GHz}\right.$ loss tangent 0.0018$)$ is used in all the simulations and fabricated prototypes. The total antenna size is also fixed to $35 \times 35 \times 1.6 \mathrm{~mm}^{3}$. A coplanar transmission line is designed to excite all the antennas and consists of a central conducting strip $(13 \mathrm{~mm} \times 4 \mathrm{~mm})$. The two symmetrical grounds around the strip have dimension of $15 \times 13 \mathrm{~mm}^{2}$ with coplanar gap of $0.5 \mathrm{~mm}$ between ground and central conducting strip to provide $50 \Omega$ impedance match. The reader should consider the same values otherwise specified wherever necessary to avoid redundancy.

A conventional coplanar monopole antenna and its return loss is presented in Fig. 2. The properties of such monopoles are mainly the function of their ground dimensions, type and size of monopole. However, the size of monopole determines the lower frequency of the bandwidth which is approximately the quarter wavelength.

A simple coplanar monopole with two symmetric sleeves as extension of ground is shown in Fig. 3 [Chen 2007]. In comparison to the return loss with coplanar monopole without 
sleeves, it is evident that an additional resonant mode at $4.95 \mathrm{GHz}$ above the fundamental mode $3.15 \mathrm{GHz}$ is also excited. The excited mode resonance frequency corresponds to the length of sleeve. Therefore, the length of sleeve can also be adjusted to achieve dual/multiband operation instead of wide-bandwidth operation. Like in this case, the bandwidth of the sleeve mode is adjusted to add up with the bandwidth of fundamental mode and wider bandwidth is achieved. The offset of sleeve from the radiator and the width of sleeve are also very important and can be adjusted to control the impedance match and bandwidth of the sleeve mode.

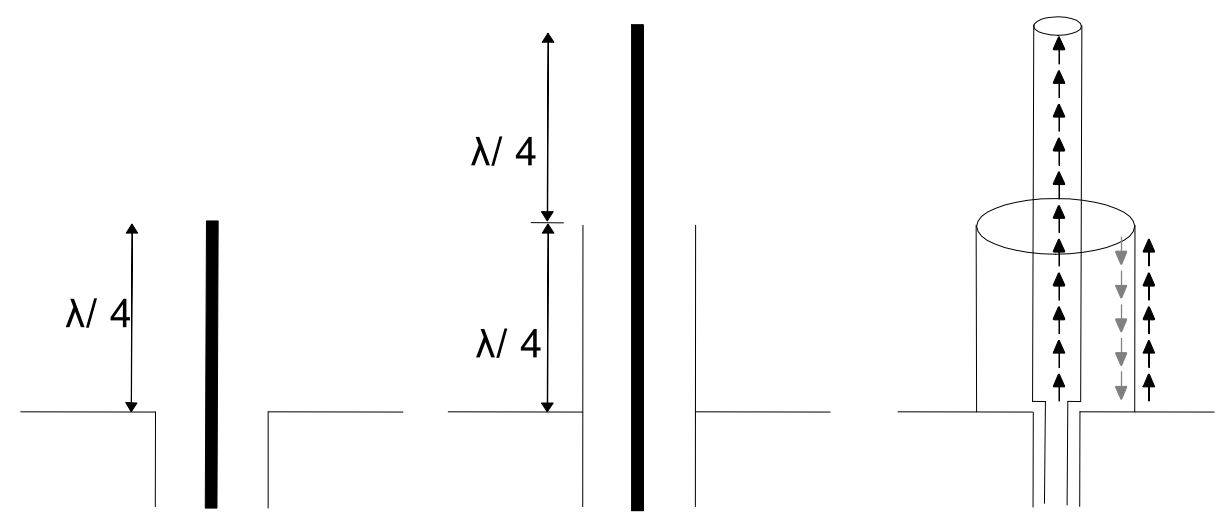

Fig. 1. Traditional monopole over the ground (left), Sleeve antenna (middle) and 3D-view (right)
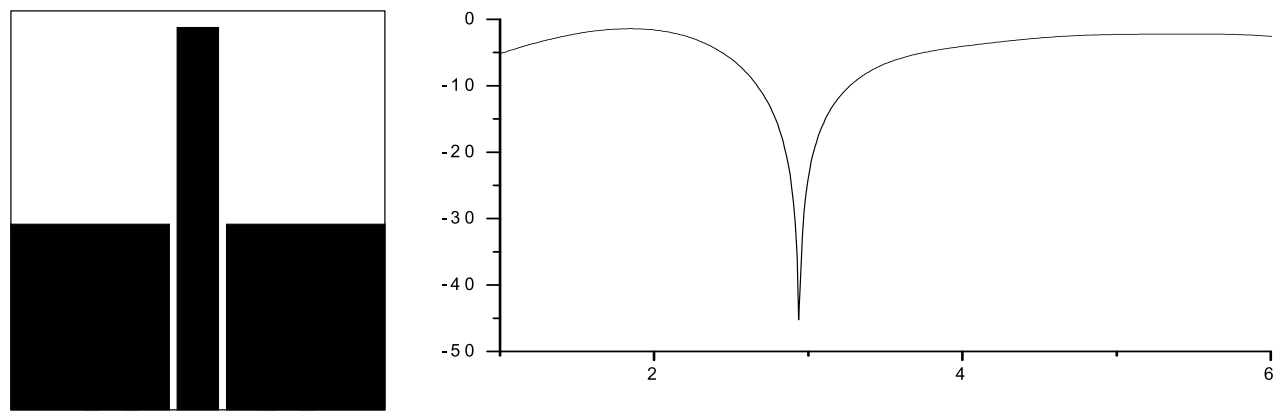

Fig. 2. Schematics (left) and return loss of traditional coplanar monopole antenna. The monopole has length of $21 \mathrm{~mm}$ and width of $4 \mathrm{~mm}$.

An insight analysis is further carried out by studying and comparing the surface current distribution of standard monopole and sleeve monopole antenna (see Fig. 4). The surface current distribution of fundamental mode for simple monopole and monopole with ground connected sleeve is quite similar. However, the surface current distribution in the ground plane for the sleeve monopole has secured a longer path as compared to conventional monopole design. The surface current distribution of sleeve mode (additional resonance mode $4.95 \mathrm{GHz}$ in Fig. 3.) at electrical length of sleeve is also excited. The fundamental mode of both of designs has surface current in the same direction (i.e. upward direction). The 
surface current of sleeve mode is opposite to fundamental mode as evident. Moreover, the sleeve surface currents on the side toward monopole are out of phase to the monopole current same as presented in Fig. 1.
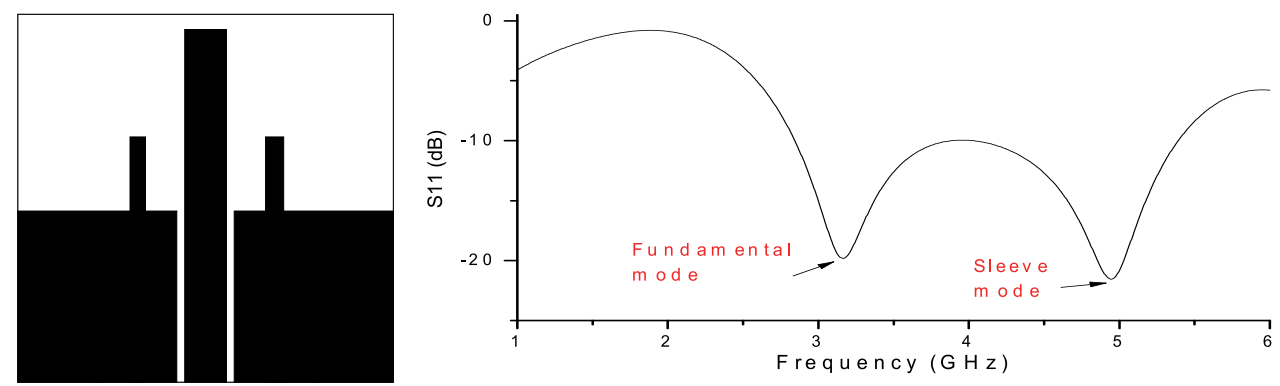

Fig. 3. Schematics of ground connected sleeve antenna and its return loss. The sleeve has length of $7.5 \mathrm{~mm}$ and width $3 \mathrm{~mm}$. The offset of sleeve from the monopole is $2.5 \mathrm{~mm}$.
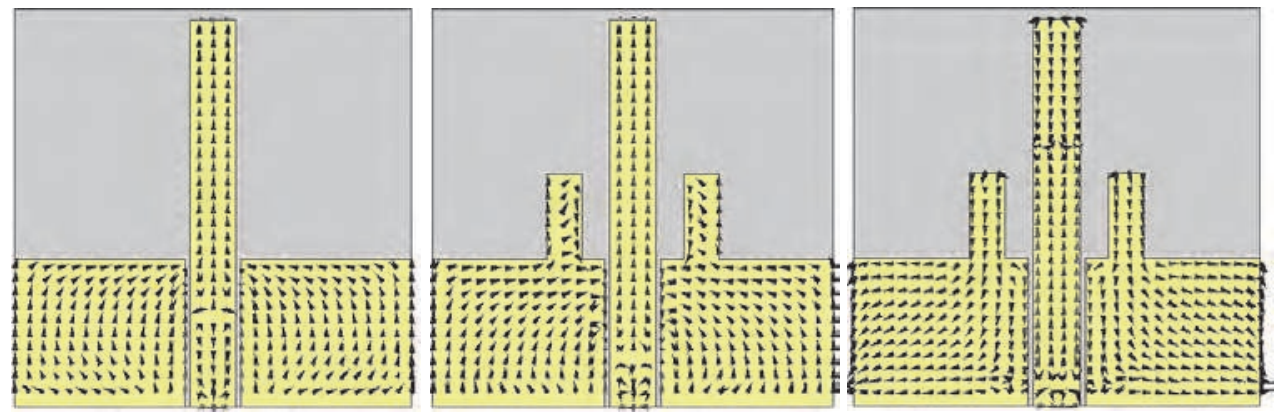

Fig. 4. Comparison of surface current distribution between simple coplanar monopole (2.8GHz left), fundamental mode of ground shorted sleeve (3.2 $\mathrm{GHz}$ middle) and sleeve mode (4.8GHz right)

Some different kinds of sleeve antenna found in literature are presented in Fig. 5. The conventional monopole design of Fig. 3 can be modified by adding multiple sleeves (Fig. 5 (a)) such that the additional modes (i.e. fundamental mode due to monopole and sleeve modes) coincide with each other to addup the impedance matching. In another type of sleeve, (Fig. 5 (b) gap sleeve) in which the sleeves are not connected to the ground rather have small gap between the sleeve and ground. This gap creates an additional parasitic element between the ground and sleeve. A similar design presented in Fig. 5 (c) utilizes combination of two sleeves. This adds an additional parameter to exploit the impedance matching of the extra resonant mode of the sleeve. Finally, inset sleeves are etched on ground opposed to traditional strip sleeves (extension of ground) are also presented. The inset sleeve moves the feed location to a virtual point that depends on the length of sleeve also shown in the figure. This leads to excitation of an additional resonant mode with electrical length (quarter wavelength) corresponding to sum of length of monopole and length of inset sleeve. Therefore, this additional resonant mode is excited before lower resonance and therefore inset sleeves can miniaturize antenna size. 

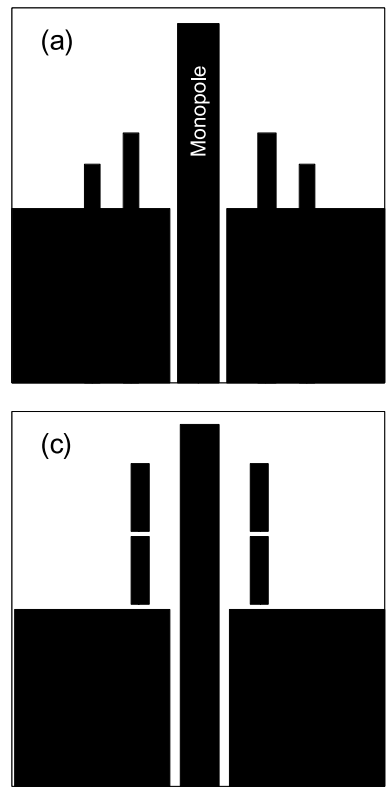
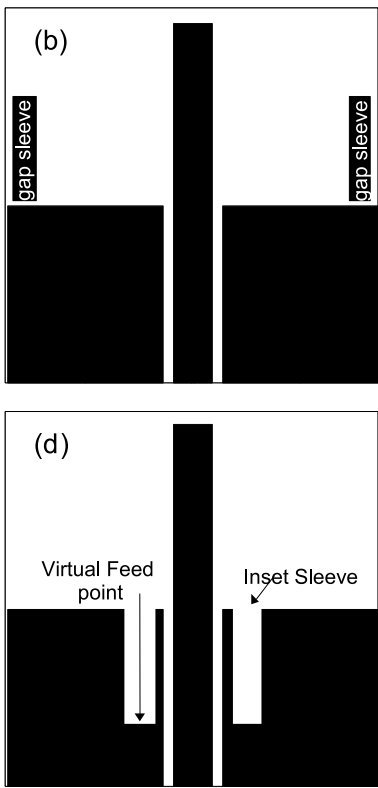

Fig. 5. Different coplanar monopole sleeve antennas. (a) double ground shorted sleeve[Dong 2009], (b) gap sleeve [Cheng 2004], (c) double gap sleeve [Yacouba 2006], and (d) inset sleeve [Baik 2008]

Before moving to sleeve UWB antennas, the reader is suggested to study the two novel design of Fig. 6 [Wu et. al., 2005, Hsiao et. al. 2006] where combination of modified monopole (T-shaped and Y-shaped) and sleeve is used to achieve desired bandwidth. Some novel applications of sleeve are also presented and to get idea of sleeves in non coplanar technology [kunda 2003, Thomas 2007].
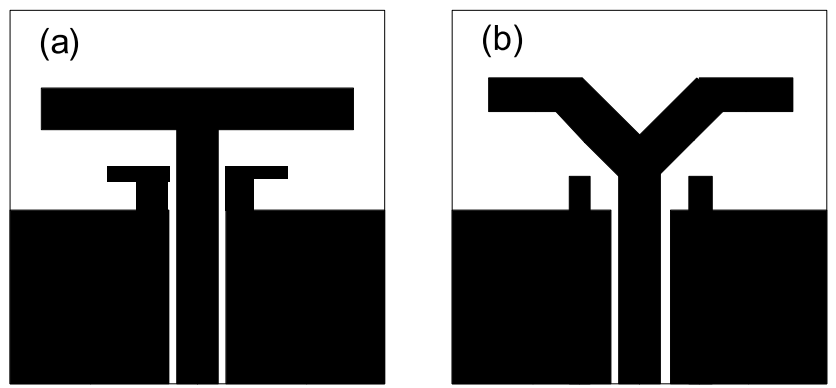

Fig. 6. T-Shaped monopole with L-shpaed sleeve (a) and Y-shaped monopole with ground connected sleeve (b)

\section{UWB antenna design}

In the recent years, sleeves have been successfully been utilized for UWB operation. Increase of several order of bandwidth is found in the literature. In general, beside some specific 
requirements for a particular application (e.g. omni-directionality for mobile terminal antenna), finalizing an antenna is on the disposal of the choice of antenna designer that depends on many factors like the requirement and time of launch of the product. This leads to limited number of research articles where the detail description of antenna designs is presented. Therefore, before jumping to the sleeve's analysis on the impedance bandwidth of an antenna, we will slightly discuss the transmission line model of antenna and theory of characteristics mode of antenna design. It will help the reader to understand the behavior of the sleeve.

\section{Transmission line model of antenna}

It becomes easy to understand and analyze the impedance behavior of antenna with the help of transmission line modeling [Ray et. al., 2001, Valderas et. al. 2006]. If we consider an antenna equivalent to a transmission line, the width of bottom profile near the ground is equivalent to the length of the transmission line. Similarly, the combination of feed gap and shape of bottom profile collectively contribute to complex impedance. It is quite difficult to formulate this impedance but TLM helps to sketch an extended picture to visualize the collective behavior the antenna. Therefore, the increase in the width of monopole antenna is same as increase in the length of transmission line that in turn increases the impedance to a higher value. The length of feed gap is an inductive parameter that shift smith chart accordingly. The large bandwidth of circular disk and elliptical monopole is understandable due to the impedance varying function away from the radiator (i.e. lateral direction). Furthermore, it is obvious to use beveling or step generated base with structures that are small bandwidth (e.g. square, rectangle etc.) to provide linearly varying characteristics impedance function of distance from feed probe. On the basis of transmission line modeling, it is understandable to use parasitic element by either modifying the radiator or ground to countermarch the radiator bandwidth deficiencies. It will be described shortly that slits and slot can be added to the monopole radiator to force the surface currents to follow a guided path for impedance matching at desired frequency or to excite extra mode for bandwidth enhancement. On the other hand, if the ground plane is to be modified for improved impedance behavior, sleeves are among the suitable candidates. Keeping in view the transmission line model of antenna, sleeves are additional parasitic elements (e.g. ground connected, gap and inset sleeve) that can be added to modify the original design to enhance the matching over the desired bandwidth.

\section{Theory of characteristics modes}

In early 1971, Garbaz et. al. formulated the theory of characteristics modes for radiated and scattered fields, refined by [Harrington et al. 1971] and finally revisited by [Valencia et. al. 2005] as a design guideline for modern antenna. Characteristics modes of antenna are the real currents on the surface of antenna, extracted from generalized impedance matrix, characterized by the shape and size of the radiator and independent of the feed location. In this modern era, simulated current help us to understand the resonance behavior of the antenna and can be re-routed to achieve desired performance. We shall discuss sleeve UWB antennas proposed in the next section on the basis of theory of characteristics modes.

Now we shift our attention on the discussion of different UWB antennas utilizing sleeves previously found in literature. The designs of such sleeve antennas are listed in Fig. 6. 
Square monopole with ground connected symmetrical sleeves initially presented by [Chen 2005] and it was proved that such antennas have improved impedance bandwidth as compared to square monopole. Square antenna with L-shaped sleeve and T-shaped slot is used to excite upto fifth resonance to obtain ultra wide bandwidth. The L-shaped sleeve enhances the electromagnetic coupling between the radiator and ground that creates broadening and electrically couples the ground with monopole. Further improvement in the design is possible with help of two T-shaped slots etched on the patch to re-route the surface current that can be used for impedance matching or excite additional modes at a desired frequency. This also improves the radiation efficiency but the resonant resistance is decreased. Recently, [Ojaroudi, 2010] proposed an antenna with stepped patch and truncated ground based on the Babinet's Equivalence Principle. The slot and slits placed one half is inverted at the other half. The sleeves manipulate the impedance bandwidth by modifying the capacitance between the modified patch and ground. The slits are used to force the surface current to follow the path which produces additional mode. Beveling square and rectangular monopoles is famous method of improving the impedance bandwidth as explained earlier in the beginning of this chapter on the basis of transmission line modeling of antenna. Impedance bandwidth is function of flare angle [Ch-8 Kraus, 1988] which in combination with feed gap in such shapes (e.g. triangle, diamond, rhombic) plays a vital role to overcome impedance mismatch and must be considered for optimization. The sleeve with beveled rectangle and truncated ground is studied [Yoon, 2010].
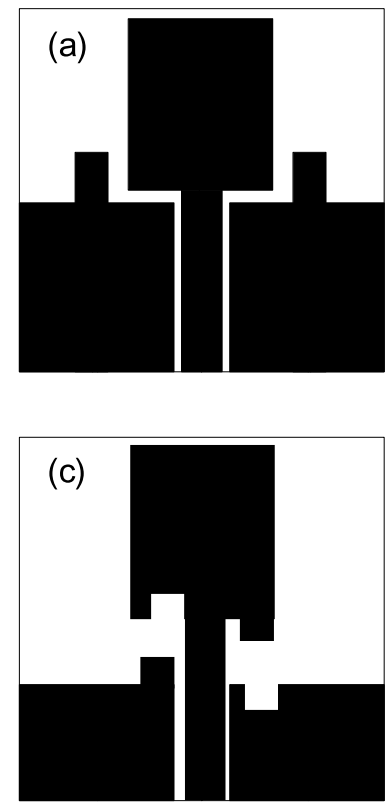
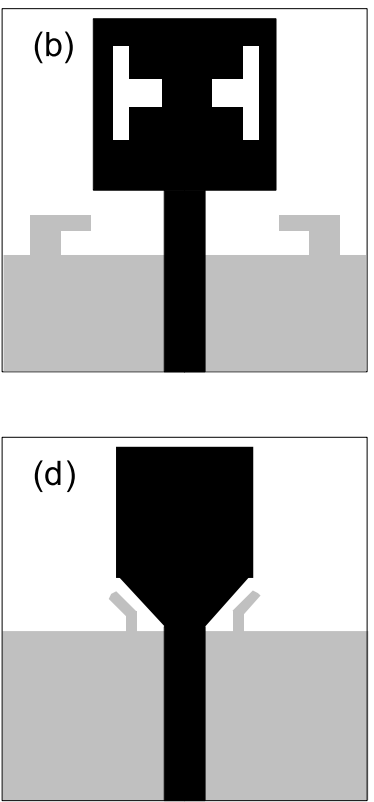

Fig. 6. Different sleeve monopole designs. (a) coplanar square monopole with ground connected sleeve [Chen, 2005], (b) microstrip square monopole with L-shaped sleeve and TShaped slot [Ebrahimian, 2010], (c) modified square monopole with slit and slot based on Babinet's principle [Ojaroudi, 2010], (d) Bevelled rectangular sleeve antenna with tilted sleeves [Yoon, 2010] 
In Fig. 7, two triangular monopoles with sleeve modification are shown. Tilted sleeves slightly offset from the radiator are applied to triangular shaped antenna, sleeves secures current path to excite resonant modes to improve the impedance bandwidth. The same shape is further studied and improved with hillside shaped corrugation and trapezoid ridged ground. The ridged ground is in form of two symmetrical corrugations extended from the top edge of flat ground plane. These modified grounds provides a smooth transitions between transmission line and free space compared to conventional design to provide the flat response of S-parameters over the wide frequency range. The author claimed to get a significant improved of $4: 1$ in impedance bandwidth.
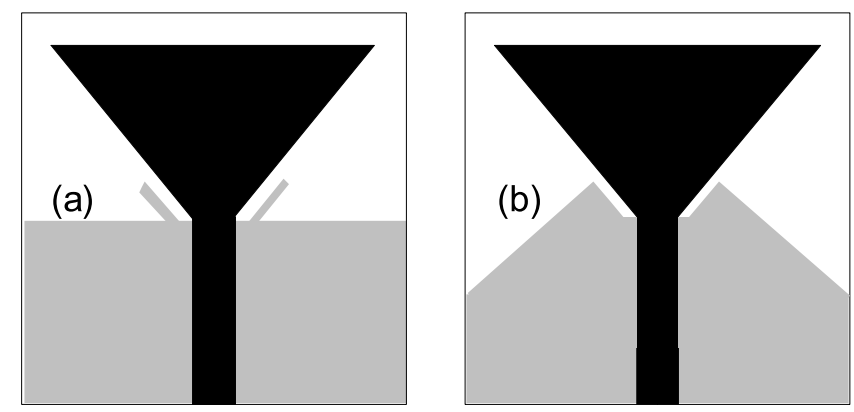

Fig. 7. Microstrip modified triangular monopole. (a) tilted offset sleeve [Lin 2008] and (b) hillside shaped corrugation and trapezoid ridged ground [Lin 2007]

Now we shift our attention towards the novel sleeve antennas (i) rectangular sleeve and (ii) diamond sleeve antenna that are presented in this chapter with special emphasis on impedance enhancement due to sleeves. Coplanar transmission line is used for the proposed antennas mainly due to their easy integration with RF-devices. However, the same treatment can also be utilized for microstrip based technology. As already discussed, several radiator designs have been implemented on microstrip and coplanar technology to study their impedance matching behavior. Among those geometries, square and rectangular monopoles are known to be of less bandwidth [Ammann et. el., 2000, Evans et. al., 1999]. Therefore, we selected rectangular and diamond shaped monopole in this chapter along with integration of different sleeve for UWB operation.

\section{Rectangular monopole with double gap sleeves}

To start with, the schematics and return loss of simple rectangle monopole is presented in Fig. 8 for different values of feed gap (i. e. distance between patch and ground). From return loss it is evident that impedance matching is not of the order of $10 \mathrm{~dB}$ and feed gap is always very important optimization parameter for such shapes and should always be considered for impedance matching. As the feed gap increases, the impedance matching improves at lower order of bandwidth and degrades at higher frequency. On the other hand, the lower resonance shifts to lower frequency due to increase in the overall dimension of the antenna. A novel UWB antenna utilizing combination of two gap sleeves is presented in Fig. 9. Compared to the previous design [Chen 2005], the gap sleeve (instead of ground connected) near the ground are utilized. This adds a parasitic element near the ground in addition to coupling between the antenna and sleeve. The impedance bandwidth is further exploited by 
adding an extra gap sleeve. Therefore, the coupling between the sleeve and monopole is divided further with another coupling element between the two sleeves. Based on the design principle, the optimization can easily be performed through simulation. The design principle is to first get optimal width of rectangle monopole as discussed in TLM method and then optimize the feed gap. Finally, use two symmetric sleeves of same length to get UWB coverage. The return loss covers the whole UWB frequency range with $10 \mathrm{~dB}$ reference. Further improvement like the mismatch around $12 \mathrm{GHz}$ is proposed by using the sleeves of different length. The normalized radiation pattern in the azimuth plane has good omnidirective coverage and is presented in Fig. 10.
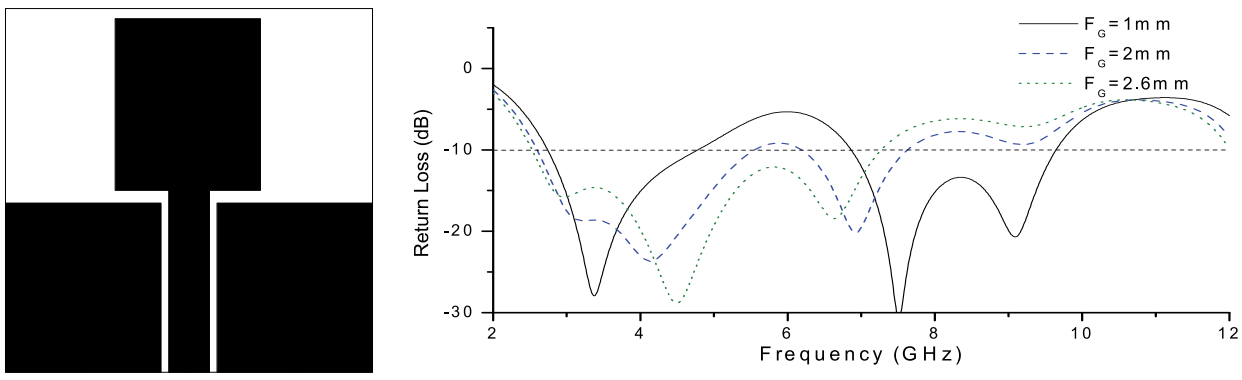

Fig. 8. The schematics of coplanar antenna with rectangle patch $(20 \mathrm{~mm} \times 15 \mathrm{~mm})$. The return loss for different values of feed gap on the right side.
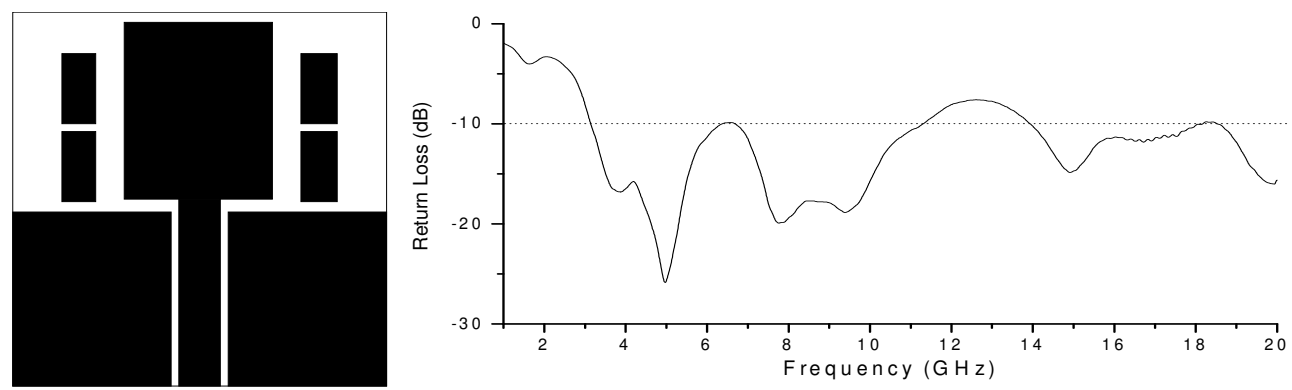

Fig. 9. Modified rectangle monopole antenna having combination of symmetric gap sleeves above the ground. Sleeves have dimension of $(6 \mathrm{~mm} \times 3 \mathrm{~mm})$ and $4 \mathrm{~mm}$ offset from the edge of the ground. Lower sleeves have gap of $0.1 \mathrm{~mm}$ from the coplanar ground and gap between the two sleeves is $0.4 \mathrm{~mm}$ (left). Return loss measurements (right)

To study modal characteristics of the antennas, the surface current distribution is presented for different frequencies. The fundamental mode has similar current distribution like wire monopole of quarter wavelength. The direction of current is vertically up the monopole with no null. At higher mode $(4.8 \mathrm{GHz})$, current appears to move at the edge of the monopole towards the bottom with a null appears at the gap between the two sleeves and the currents are in opposite direction. This also suggests changing the length of sleeve to vary the frequency of resonance of sleeve modes. The mode at $(7.1 \mathrm{GHz})$ is appears to be out of phase replica of $4.8 \mathrm{GHz}^{\prime}$ s mode. At even higher frequencies (i.e. $10 \mathrm{GHz}$ ), the number of nulls increases and variation of surface current in the coplanar ground is evident. The poor 
radiation performance of antenna at high frequency (e.g. pattern at $9 \mathrm{GHz}$ in Fig. 10) can also be considered as direct consequence of degraded surface current. The modal behavior of monopole with sleeves is slightly different from the simple monopole designs (Fabrés et. al., 2002, Lu et. al., 2009).

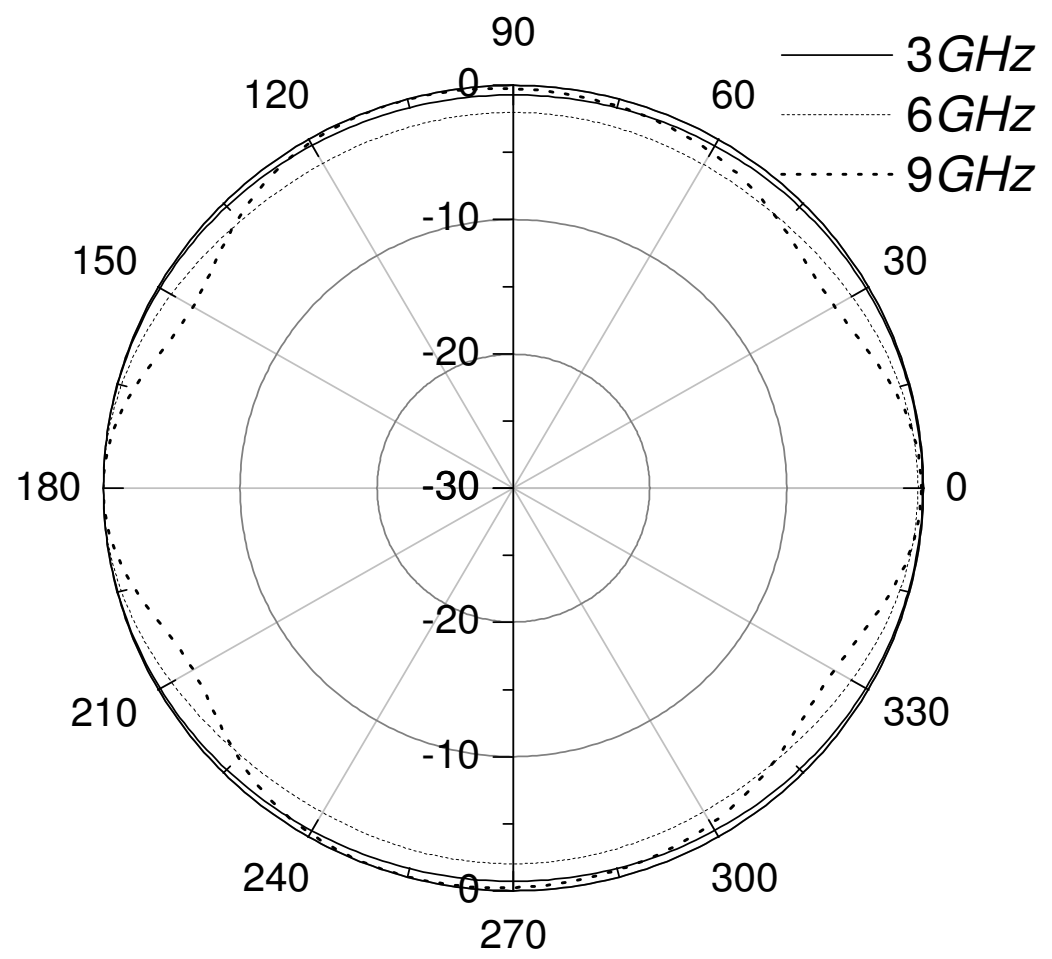

Fig. 10. Azimuth (H-Field) plane normalized pattern of the proposed design.

\section{Diamond monopole with tilted gap sleeves}

The bandwidth of square/rectangle monopole can be improved by modifying it to diamond shaped radiator. The diamond shape of the proposed antenna is obtained by cutting the lower and the upper vertex of a square rotated to $45^{\circ}$ (see the shaded area on the left side of Fig. 12 ). The height of bottom cut $\left(H_{L}\right)$ forces the concentration of current distribution near the bottom edge of the diamond monopole that improves impedance bandwidth. The height of upper cut can be optimized either for compactness or further impedance match at high frequencies. The return loss of diamond monopole with different value of $H_{L}$ is presented in Fig. 13. The impedance matching becomes better for $H_{L}=3 \mathrm{~mm}$. On the basis of transmission line model, the height of lower cut in conjunction with feed gap counter matches the increase in the impedance of transmission line due to increase in size of monopole in the lateral direction compared to the rectangular monopole. However, the higher values of $H_{L}$ shift the lower frequency of impedance bandwidth to higher value due to overall decrease in the size of antenna. 

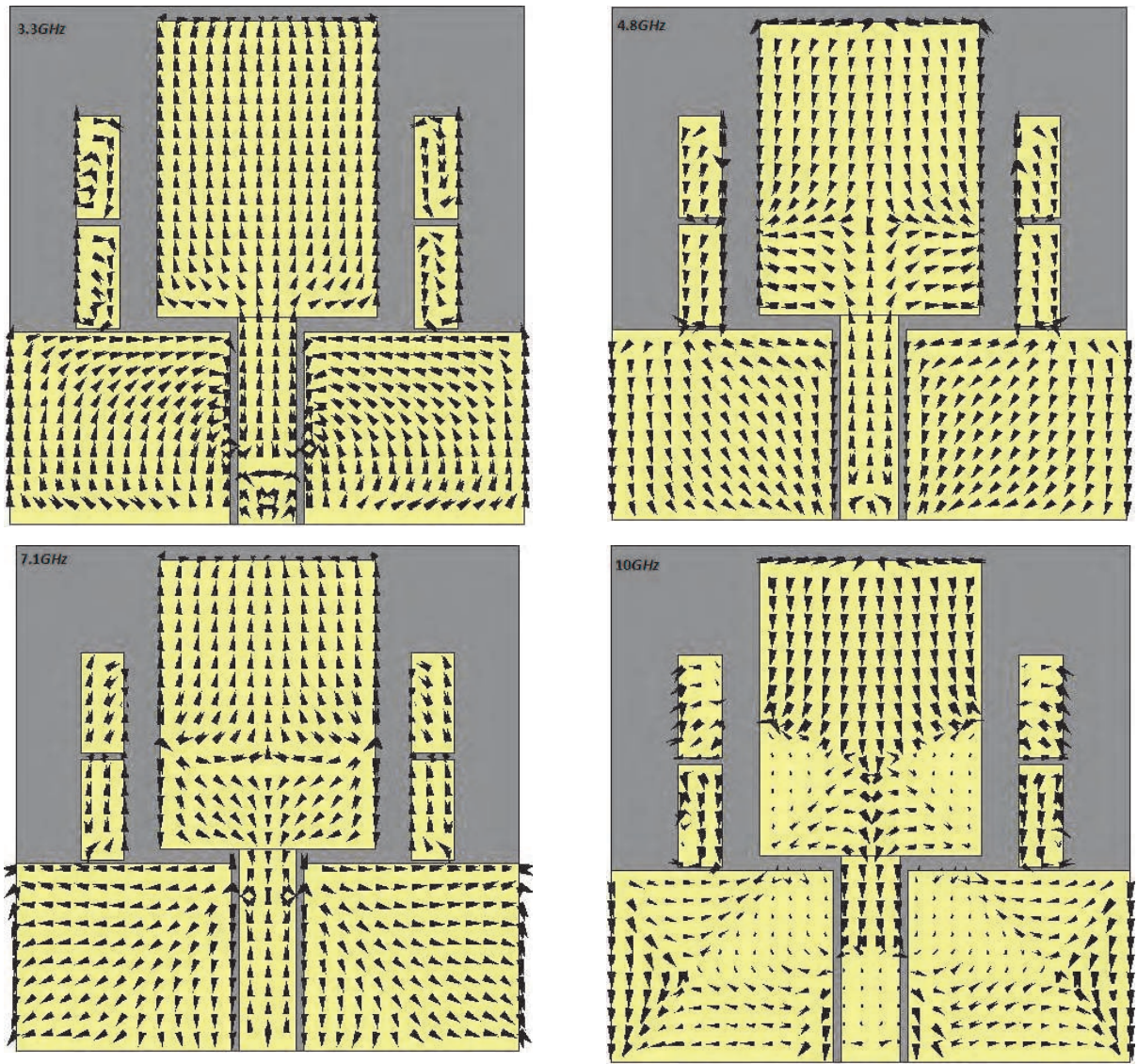

Fig. 11. Surface current distribution of square monopole with two gap strips above each of coplanar ground.
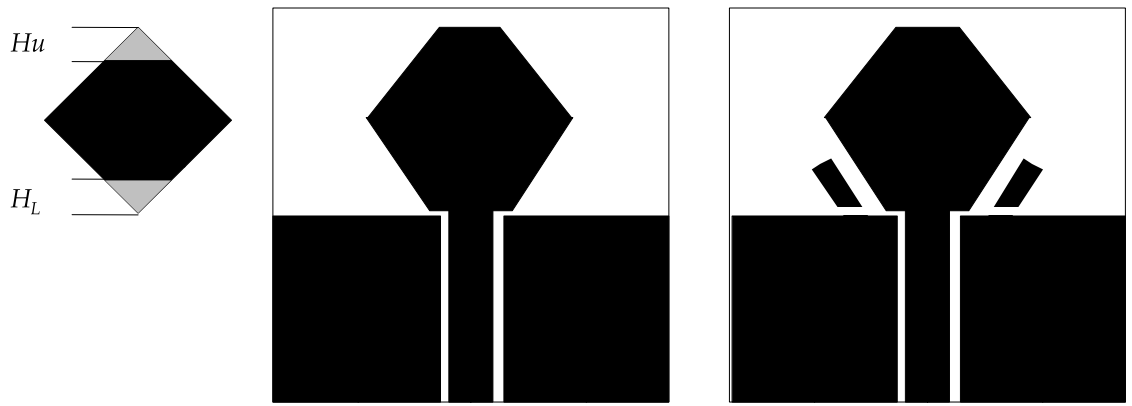

Fig. 12. Schematics of diamond shaped monopole with symmetrical tilted gap sleeves. The tilted gap sleeve has length of $7 \mathrm{~mm}$. Sleeve offset from ground and diamond monopole is $0.5 \mathrm{~mm}$ and $0.75 \mathrm{~mm}$ 


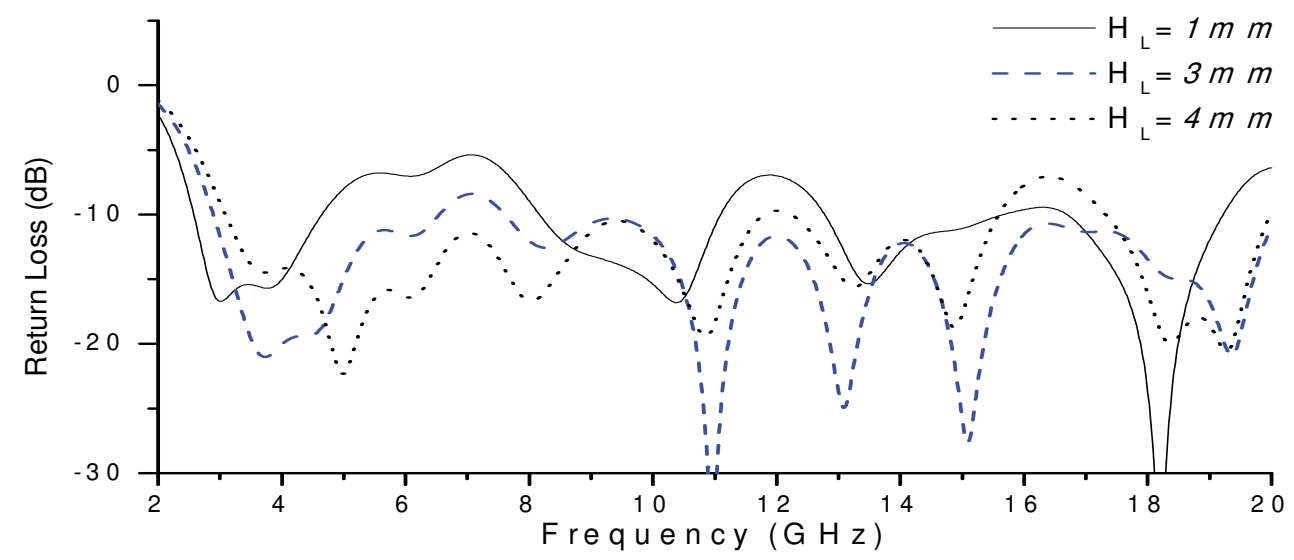

Fig. 13. Return loss for different values of $H_{L}$. The value of $H_{U}$ is fixed to $4 \mathrm{~mm}$.

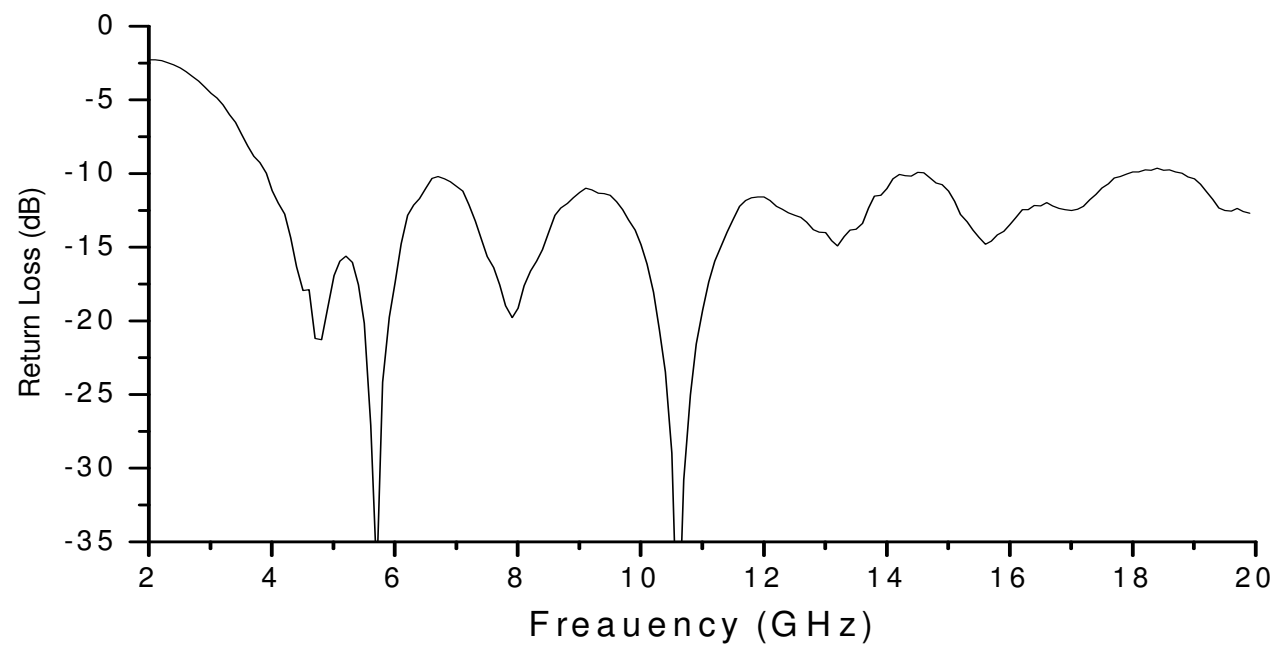

Fig. 14. Return loss of proposed diamond shaped monopole with tilted gap sleeves.

For a square like design, impedance matching upto 20GHz represents good improvement over the conventional small bandwidth square designs (Fig. 14). The values of $H_{L}$ and $H_{U}$ are $3 \mathrm{~mm}$ and $4 \mathrm{~mm}$ respectively for rectangle of $(20 \mathrm{~mm} \times 15 \mathrm{~mm})$. Coplanar transmission line of $50 \Omega$ is design with central conducting strip of dimension $(19.5 \mathrm{~mm} \times 2 \mathrm{~mm})$ and a gap of $0.25 \mathrm{~mm}$ between the central conducting strip and ground. Tilted gap sleeves have dimension of $(7 \mathrm{~mm} \times 2 \mathrm{~mm})$ with gap of $2 \mathrm{~mm}$ from the ground. Finally, the radiation pattern in the azimuth plane presented in Fig. 15 shows typical omni-directional radiation performance usually required for general UWB communication systems. Both of the designs discussed here have typical butterfly like pattern in the Elevation plane and therefore not shown. 


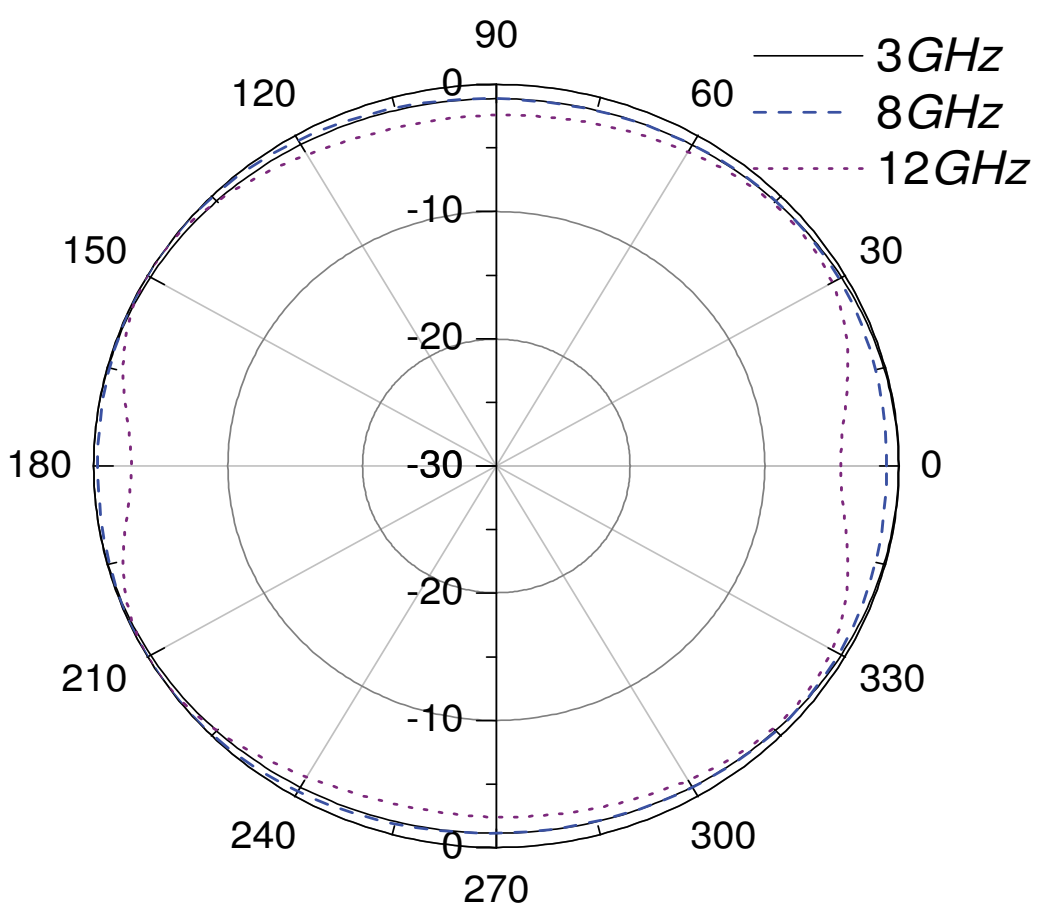

Fig. 15. Azimuth radiating pattern (H-plane) of the proposed diamond shaped coplanar antenna with tilted shapes normalized to $0 d B$.

\section{Conclusion}

Sleeves have been considered a step head than their traditional role in the antenna design. Novel rectangle and diamond shaped monopoles with sleeves are presented with in-depth analysis based on modal and transmission line model.

\section{Acknowledgment}

We are extremely grateful to management of School of Electrical Engineering and Computer Science (SEECS), National University of Sciences and Technology (NUST), Pakistan, for providing access and technical assistance in performing test and measurements at the Research Institute for Microwave and Millimeter-wave Studies (RIMMS). We are also thankful to Mr. Malik Abdul Shakoor and Mr. Syed Zubair Hussain at National Institute of Electronics, Islamabad, Pakistan for fabricating the PCB's.

\section{Reference}

Ammann M. J., (2000), "Impedance bandwidth of the square planar monopole", Microwave and Optical Technology Letters, Vol. 24, No. 3, pp. 183-187, ISSN: 1098-2760. 
Baik J. W. \& Kim Y. S., (2008), “Printed Inset Sleeve Monopole Antennas for Dual-Band Applications," Microwave and Optical Technology Letters, Vol. 50, No. 8, pp. 19951997, ISSN: 1098-2760.

Bock, E. L., Nelson, J. A., \& Dorne, A., (1947), Chapter 5, "Sleeve antennas, in Very High Frequency Techniques", McGraw Hill, pp. 119-137, New York.

Chen, H. D. \& Chen, W. S., (2007), "Ultra-Wideband Design of Sleeve Monopole Antenna", IEEE Transactions on Antennas and Propagation, Vol. 54, No. 3, pp. 1034-1037, ISSN: 0018-926X.

Chen S. B., Jiao Y. C., Wang W., \& Liu Q.Z., (2005), “Wideband Cpw-Fed Uniplanar SleeveShaped Monopole Antenna", Microwave and Optical Technology Letters, Vol. 47, No. 3, (November), pp. 245-247. ISSN: 1098-2760.

Cheng C. H., Lu W. J., Chen Y., \& Zhu H. B., (2004) “A Dual-Band Strip-Sleeve Monopole Antenna Fed By Cpw", Microwave and Optical Technology Letters, Vol. 42, No. 1, (July), pp. 70-72, ISSN: 1098-2760.

Dong T., Chen Y.-P., (2009) “Novel Design of UWB Printed Double Sleeve Monopole Antenna", Progress in Electromagnetics Research Letters, Vol. 9, pp. 165-173, ISSN: 1937-6480.

Ebrahimian H. \& Ojaroudi M., (2010), “Design Of A Novel Ultra-Wideband Printed Monopole Antenna For Use In A Circular Cylindrival Microwave Imaging Syetem", 6 $6^{\text {th }}$ International Workshop On Biological Effects Of Electromagnetic Fields Kefaluka Resort, Turkey, (October).

Evans, J. A. \& Ammann, M. J., (1999), “Trapezoidal and pentagonal monopoles with impedance bandwidths in excess of 10:1", IEEE Antennas Propagation Society International Symposium, Vol. 3, pp. 1558-1561, ISBN: 0-7803-5639-x.

Federal Communications Commission (2002), Revision of Part 15 of the Commission's Rules Regarding Ultra-Wideband Transmission Systems, First Report and Order, FCC 02-48.

Garbacz, R. J., \& Turpin, R. H. (1971), “A generalized expansion for radiated and scattered fields", IEEE transactions on Antennas and Propagation, Vol. AP-19, pp. 348-358, ISSN: 0018-926X.

Guo, J., Ji, Y. \& Liu, Q., (2003), “Sleeve monopole antennas at the center of a circular ground plane", Microwave and Optical Technology Letters, Vol. 38, No. 4, (August), pp. 341343, ISSN: 1098-2760.

Harrington, R. F., \& Mautz, J. R., (1997), “Theory of characteristics modes for conducting bodies", IEEE transactions on Antenna and Propagation, Vol. 19, pp. 622-628, ISSN 0018-926X.

Hsiao H. M.,Lu J. H, Wu J. W., (2006), “Y-shaped monopole antenna with dual-broadband operation for WLAN", Microwave and Optical Technology Letters, Vol. 48, No. 8, (August), pp. 1476-1480, ISSN: 1098-2760.

Fabrés M. C., Daviu E. A., Norueira A. V. \& Bataller M. F., (2005), "The theory of characteristic modes revisited: A contribution to the design of antennas for modern applications", IEEE antenna and propagation magazine, Vol. 49, No. 5, (October), pp. 52-66, ISSN 1045-9243, OCLC: 20287815.

Fabrés M. C., Daviu E. A., Norueira A. V. \& Bataller M. F., (2002), “Systematic study of elliptical loop antennas using characteristics modes", Antennas and Propagation Society International Symposium, Vol. 1, pp. 156-159, ISBN: 0-7803-7330-8. 
Honda, S., Ito, M. \& Jinbo, Y., (1992), “A Disk Monopole Antenna with 1:8 Impedance Bandwidth and Omni-directional radiation pattern", Proceedings of International Symposium Antennas Propagation, Sapporo, pp. 1145-1148, Japan.

King, R. W. P., and Wu, T. T., (1965), “The cylindrical antenna with arbitrary driving point," IEEE Transactions on Antennas Propagation, Vol. AP-13, (September), pp. 710-718, ISSN: 0018-926X.

Kraus J. D. (1988), "Antenna theory", (second edition), McGraw Hill International Edition, (ISBN 0-07035422-7), New York.

Kunda V. K., Ali M., Hwang H. S., \& Sittironnarit T., (2003), "Study of a dual-band packaged Patch antenna on a pc card for 5-6 GHz wireless LAN applications", Microwave and Optical Technology Letters, Vol. 37, No. 6, (June),pp. 423-428, ISSN: 1098-2760.

Li J.-Y. \& Gan Y.-B., (2006), "Multi-Band Characteristic of Open Sleeve Antenna”, Progress in Electromagnetics Research, PIER 58, pp. 135-148, ISSN: 1070-4698.

Lin C. C. \& Chuang H. R., (2008), “A 3-12GHz UWB Planar Triangular Monopole Antenna With Ridged Ground-Plane", Progress in Electromagnetics Research, PIER 83, pp. 307321, ISSN: 1070-4698.

Lin C. C., Kan K. Y., \& Chuang H. R., (2007), “A 3-8 GHz Broadband Planar Triangular Sleeve Monopole Antenna for UWB Communication", Antennas and Propagation Society International Symposium, pp. 4741-4744, Honolulu, ISBN: 978-1-4244-0877-1.

Lu, Y., Huang, Y. C., \& Chattha, H. T., (2009), “A further study of plnanar monopole antennas", Antennas \& Propagation Conference, Loughborough, pp. 353-356, ISBN: 978-1-4244-2720-8.

Milligan, T. A., (2005), "Modern antenna design", (Second Edition), A John Wiley \& Sons, INC., Publication, (ISBN-13 978-0-471-45776-3), America.

Norgorden, O.\& Walters, W., (1950), "Experimentally determined characteristics of cylindrical sleeve antennas", Journal of the American Society for Naval Engineers, Vol.62, No. 2, (May), pp. 365-382.

Ojaroudi M., Ebrahimian H., Ghobadi Ch., \& Nourinia J., (2010), “Small Microstrip-Fed Printed Monopole Antenna For UWB Application", Microwave and Optical Technology Letters, Vol. 52, No. 8, (August), pp. 1756-1761, ISSN: 1098-2760.

Poggio, A. J. \& Mayes, P. E., (1966), "Pattern bandwidth optimization of the sleeve monopole antenna," IEEE Transactions on Antennas Propagation, Vol. AP-14, No. 5, (September), pp. 643-645, , ISSN: 0018-926X.

Qiao W., Chen Z. N., \& Wu K., (2006), "UWB monopole antenna with a top-hat sleeve”, International Journal of Microwave and Optical Technology, Vol. 1, No. 1, pp. 17-27, ISSN: 1098-2760.

Rispin I. W., \& Chang D. C., (1998), "Wire and loop antennas in antenna handbook", pp. 723-736, New York.

Ray K. P., Anob P. V., Kapur R., \& Kumar G., (2000) “Broadband Planar Rectangular Monopole Antennas", Microwave and Optical Technology Letters, Vol. 28, No. 1, (January), pp. 55-59, ISSN: 1098-2760.

Shen Z., (2001), "Theoretical Modeling of Multi-Sleeve Monopole Antennas", Progress in Electromagnetics Research, PIER 31, pp. 31-54. ISSN: 1070-4698.

Thomas K. G \& Lenin N., (2007), "Ultra wideband folded rectangular monopole”, Microwave and Optical Technology Letters, Vol. 49, No. 6, (June), pp. 1497-1500, ISSN: 1098-2760. 
Valderas D. (2006), "Design of UWB folded plate monopole antennas based on TLM", IEEE transactions on Antenna and propagation, Vol. 54, No. 6. pp. 1676 - 1687, ISSN: 0018926X.

Wu J. W.,Wang W. D.,Hsiao H. M. \& Lu J. H.,(2005), “T-shaped monopole antenna with shorted L-shaped strip-sleeves for WLAN 2.4/5.8-GHz operation", Microwave and Optical Technology Letters, Vol. 46, No. 1, (July),pp. 65-69, ISSN: 1098-2760

Wunsch, A. D., (1988), "Fourier series treatment of the sleeve monopole antenna", Proceedings of International Electrical Engineering, Vol. 135, No. 4, (August), pp. 217225.

Yacouba C., Tayeb A. D., \& Larbi T. (2006), “Broadband Coplanar Waveguide-Fed Printed Monopole Antenna with Strip-Sleeves", Microwave and Optical Technology Letters, Vol. 48, No. 2, pp. 209-212, ISSN: 1098-2760.

Yoon H. K., Park J. A., Lim Y., Yoon Y. J., \& Lee C. H., (2010), "miniaturization of a ultra wide band antenna", PIERS Proceedings, Cambridge, USA, (July), ISSN1931-7360

Zachou V., Christodoulou C. G., Chryssomallis M. T., Anagnostou D., \& Barbin S. (2006), "Planar monopole antenna with attached sleeves", IEEE Antennas and Wireless Propagation Letters, Vol. 5, pp. 286-289, ISBN 1536-1225

Zhong S. S., (2010), Ch. 3., "Microwave and Millimeter wave technologies: Modern UWB antenna and equipment", In-Tech, pp. 63-82, ISBN 978-953-7619-34-3, Vienna, Austria.

Zuo S., Zhang Z., \& Yin Y., (2006), “Bandwidth enhancement of a planar sleeve monopole antenn for wireless communication applications", Microwave and Optical Technology Letters, Vol. 52, No. 10, (October), pp. 2235-2238, ISSN: 1098-2760. 


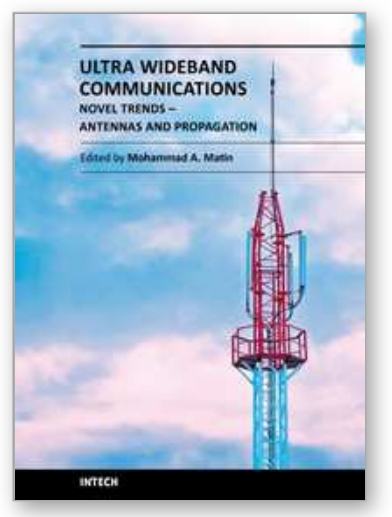

\section{Ultra Wideband Communications: Novel Trends - Antennas and Propagation}

Edited by Dr. Mohammad Matin

ISBN 978-953-307-452-8

Hard cover, 384 pages

Publisher InTech

Published online 09, August, 2011

Published in print edition August, 2011

This book explores both the state-of-the-art and the latest achievements in UWB antennas and propagation. It has taken a theoretical and experimental approach to some extent, which is more useful to the reader. The book highlights the unique design issues which put the reader in good pace to be able to understand more advanced research.

\section{How to reference}

In order to correctly reference this scholarly work, feel free to copy and paste the following:

Salman Naeem Khan and Muhammad Ashfaq Ahmed (2011). Printed Sleeve Monopole Antenna, Ultra Wideband Communications: Novel Trends - Antennas and Propagation, Dr. Mohammad Matin (Ed.), ISBN: 978-953-307-452-8, InTech, Available from: http://www.intechopen.com/books/ultra-widebandcommunications-novel-trends-antennas-and-propagation/printed-sleeve-monopole-antenna

\section{INTECH}

open science | open minds

\section{InTech Europe}

University Campus STeP Ri

Slavka Krautzeka 83/A

51000 Rijeka, Croatia

Phone: +385 (51) 770447

Fax: +385 (51) 686166

www.intechopen.com

\section{InTech China}

Unit 405, Office Block, Hotel Equatorial Shanghai

No.65, Yan An Road (West), Shanghai, 200040, China

中国上海市延安西路65号上海国际贵都大饭店办公楼 405 单元

Phone: +86-21-62489820

Fax: +86-21-62489821 
(C) 2011 The Author(s). Licensee IntechOpen. This chapter is distributed under the terms of the Creative Commons Attribution-NonCommercialShareAlike-3.0 License, which permits use, distribution and reproduction for non-commercial purposes, provided the original is properly cited and derivative works building on this content are distributed under the same license. 